\title{
Photoelectrochemical water splitting and hydrogen generation by a spontaneously formed InGaN nanowall network
}

N.H. Alvi, P.E. D. Soto Rodriguez, Praveen Kumar, V.J. Gomez, P. Aseev, A.H. Alvi, M.A. Alvi, Magnus Willander and R. Noetzel

\section{Linköping University Post Print}

\section{Tweet}

N.B.: When citing this work, cite the original article.

Original Publication:

N.H. Alvi, P.E. D. Soto Rodriguez, Praveen Kumar, V.J. Gomez, P. Aseev, A.H. Alvi, M.A. Alvi, Magnus Willander and R. Noetzel, Photoelectrochemical water splitting and hydrogen generation by a spontaneously formed InGaN nanowall network, 2014, Applied Physics Letters, (104), 22, 223104.

http://dx.doi.org/10.1063/1.4881324

Copyright: American Institute of Physics (AIP) http://www.aip.org/

Postprint available at: Linköping University Electronic Press

http://urn.kb.se/resolve?urn=urn:nbn:se:liu:diva-108928 


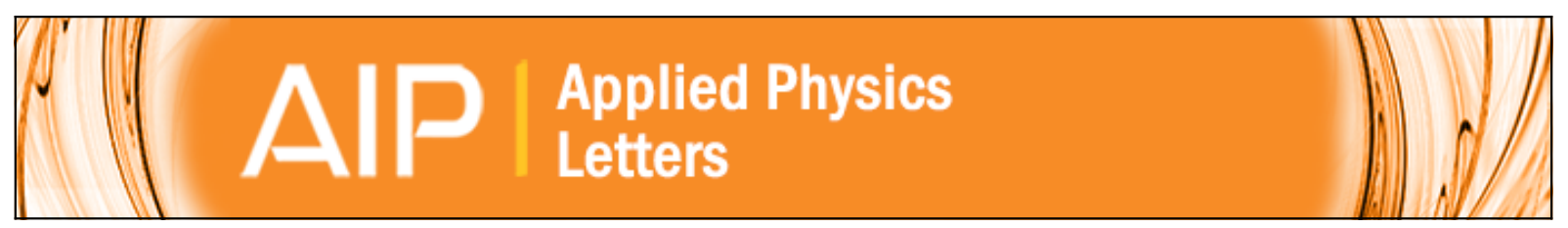

\section{Photoelectrochemical water splitting and hydrogen generation by a spontaneously formed InGaN nanowall network}

N. H. Alvi, P. E. D. Soto Rodriguez, Praveen Kumar, V. J. Gómez, P. Aseev, A. H. Alvi, M. A. Alvi, M. Willander, and R. Nötzel

Citation: Applied Physics Letters 104, 223104 (2014); doi: 10.1063/1.4881324

View online: http://dx.doi.org/10.1063/1.4881324

View Table of Contents: http://scitation.aip.org/content/aip/journal/apl/104/22?ver=pdfcov

Published by the AIP Publishing

\section{Articles you may be interested in}

Realizing InGaN monolithic solar-photoelectrochemical cells for artificial photosynthesis

Appl. Phys. Lett. 104, 143901 (2014); 10.1063/1.4871105

Significantly enhanced performance of an InGaN/GaN nanostructure based photo-electrode for solar power hydrogen generation

Appl. Phys. Lett. 103, 133904 (2013); 10.1063/1.4823550

Spontaneous formation of InGaN nanowall network directly on $\mathrm{Si}$

Appl. Phys. Lett. 102, 173105 (2013); 10.1063/1.4803017

Improved photovoltaic effects in InGaN-based multiple quantum well solar cell with graphene on indium tin oxide nanodot nodes for transparent and current spreading electrode

Appl. Phys. Lett. 102, 031116 (2013); 10.1063/1.4789502

Hydrogen generation by solar water splitting using $p$-InGaN photoelectrochemical cells

Appl. Phys. Lett. 96, 052110 (2010); 10.1063/1.3304786

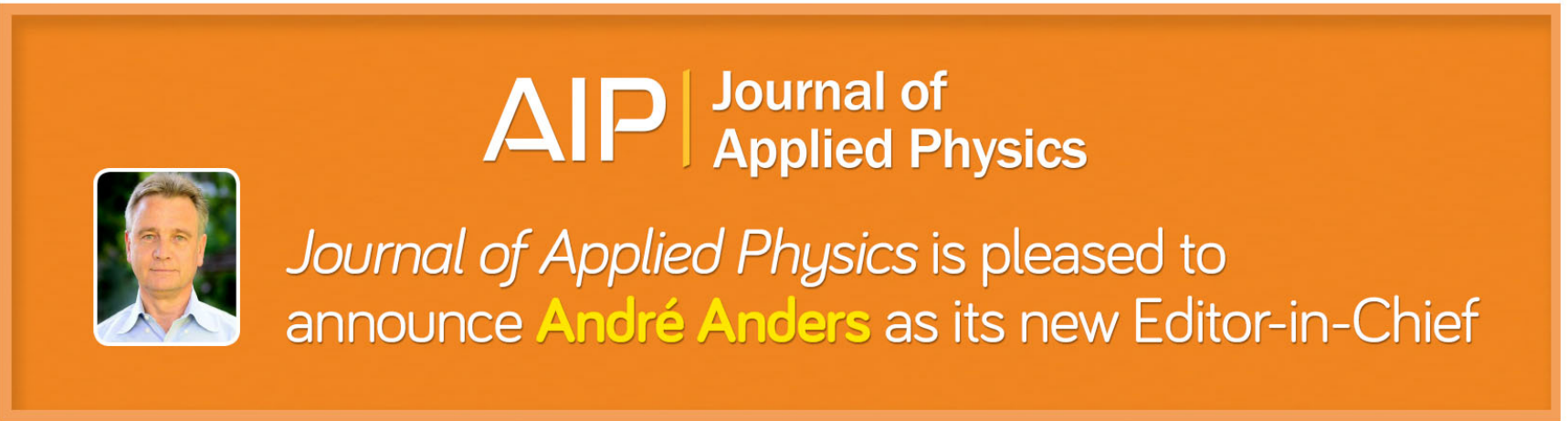




\title{
Photoelectrochemical water splitting and hydrogen generation by a spontaneously formed InGaN nanowall network
}

\author{
N. H. Alvi, ${ }^{1, a)}$ P. E. D. Soto Rodriguez, ${ }^{1}$ Praveen Kumar, ${ }^{1}$ V. J. Gómez, ${ }^{1}$ P. Aseev, ${ }^{1}$ \\ A. H. Alvi, ${ }^{2}$ M. A. Alvi, ${ }^{3}$ M. Willander, ${ }^{4}$ and R. Nötzel ${ }^{1, a)}$ \\ ${ }^{1}$ ISOM Institute for Systems Based on Optoelectronics and Microtechnology, ETSI Telecomunicación, \\ Universidad Politécnica de Madrid, Ciudad Universitaria s/n, 28040 Madrid, Spain \\ ${ }^{2}$ Department of Physics, Government College University, Faisalabad, Pakistan \\ ${ }^{3}$ Department of Chemistry, Government College University, Faisalabad, Pakistan \\ ${ }^{4}$ Department of Science and Technology (ITN), Campus Norrköping, Linköping University, \\ 60174 Norrköping, Sweden
}

(Received 11 December 2013; accepted 14 May 2014; published online 4 June 2014)

\begin{abstract}
We investigate photoelectrochemical water splitting by a spontaneously formed In-rich InGaN nanowall network, combining the material of choice with the advantages of surface texturing for light harvesting by light scattering. The current density for the InGaN-nanowalls-photoelectrode at zero voltage versus the $\mathrm{Ag} / \mathrm{AgCl}$ reference electrode is $3.4 \mathrm{~mA} \mathrm{~cm} \mathrm{~cm}^{-2}$ with an incident-photon-to-current-conversion efficiency (IPCE) of $16 \%$ under $350 \mathrm{~nm}$ laser illumination with $0.075 \mathrm{~W} \cdot \mathrm{cm}^{-2}$ power density. In comparison, the current density for a planar InGaN-layer-photoelectrode is $2 \mathrm{~mA} \mathrm{~cm}^{-2}$ with IPCE of $9 \%$ at zero voltage versus the $\mathrm{Ag} / \mathrm{AgCl}$ reference electrode. The $\mathrm{H}_{2}$ generation rates at zero externally applied voltage versus the Pt counter electrode per illuminated area are 2.8 and $1.61 \mu \mathrm{mol} \cdot \mathrm{h}^{-1} \cdot \mathrm{cm}^{-2}$ for the InGaN nanowalls and InGaN layer, respectively, revealing $\sim 57 \%$ enhancement for the nanowalls. (C) 2014 AIP Publishing LLC. [http://dx.doi.org/10.1063/1.4881324]
\end{abstract}

Solar energy driven photoelectrochemical (PEC) splitting of water for $\mathrm{H}_{2}$ generation is a clean, renewable approach for sustainable energy provision. ${ }^{1-5}$ Semiconductor nanostructures have been studied extensively in recent years for PEC cells due to their distinctive properties and promise to offer superior PEC performance. ${ }^{6-12}$ The main requirement of the PEC industry is to find semiconductor materials with the capability of efficient and cost effective conversion of sunlight to $\mathrm{H}_{2}$ by splitting water. ${ }^{13-15} \mathrm{GaInP}$ has been reported as an attractive PEC electrode material but it has unacceptably high corrosion rates and suffers from poor stability. ${ }^{16,17}$ In comparison, $\mathrm{TiO}_{2}$ has high corrosion resistance $^{17}$ but it has a large bandgap energy of $3.2 \mathrm{eV}$ allowing only for absorption of $3 \%$ of solar radiation. ${ }^{17}$ Recently, GaN has been considered as a promising PEC electrode material, but also has a too large bandgap energy. ${ }^{18-22}$

Therefore, considering the general requirements for efficient PEC water splitting, InGaN appears to be ideal with a bandgap energy tunable through the whole solar spectrum upon In composition, a large absorption coefficient, high carrier mobility, and good corrosion resistance. However, up to now there are only very few reports on the feasibility of solar water splitting using InGaN alloys. ${ }^{23,24}$ Regarding the In composition, $40 \%-50 \%$ is optimum balancing the bandgap energy to be large enough to maintain a sufficiently large over-potential against the redox potential of water $\left(\mathrm{V}_{\text {redox }}=1.23 \mathrm{~V}\right)^{3}$ while being low enough for efficient absorption of solar radiation. Moreover, for In compositions in excess of about $40 \%-50 \%$, there is a high density of positively charged surface donor states likely facilitating the

\footnotetext{
a) Authors to whom correspondence should be addressed. Electronic addresses: nhalvi@isom.upm.es and r.noetzel@isom.upm.es. Tel. +34 915495700 ext.8065.
}

oxidation of $\mathrm{O}^{2-}$, i.e., the acceptance of electrons. In addition, various InGaN-based nanostructures have been reported, including nanowalls, nanoflakes, and nanowires with the potential to enhance the redox reaction due to enhanced light absorption by light scattering and enlarged surface area. ${ }^{25}$ In particular, nanowall structures are proposed as promising materials considering the requirements of PEC cells. ${ }^{26-28}$

Here, we demonstrate experimentally the enhanced PEC water splitting and $\mathrm{H}_{2}$ generation by using an InGaNnanowalls-photoelectrode with In composition up to $40 \%$. The InGaN-nanowalls-photoelectrode exhibits a significantly larger current density, higher incident-photon-to-current-conversion efficiency (IPCE), and higher $\mathrm{H}_{2}$ generation rate in comparison with a planar InGaN-layer-photoelectrode with similar In composition.

Growth, structural, and optical properties of the InGaN nanowalls and planar InGaN layer have been reported in detail in Refs. 29 and 30. Growth was performed by plasma assisted molecular beam epitaxy (PA-MBE) at $450{ }^{\circ} \mathrm{C}$ under slightly N-rich conditions on Si (111) and (0001) GaN/sapphire substrates, respectively. The In composition was 40\%-50\%. The bandgap energy of the InGaN nanowall structure and that of the InGaN layer is $\sim 1.4 \mathrm{eV}$, determined from photoluminescence measurements, implying absorption up to near-infrared wavelengths. Al contacts were deposited on the InGaN nanowalls and $\mathrm{InGaN}$ layer with excellent Ohmic behavior due to the high n-type conductivity commonly established in highIn-composition InGaN layers due to native defects. PEC characterizations were performed in a $0.5 \mathrm{~mol} \cdot \mathrm{l}^{-1} \mathrm{HBr}(\mathrm{pH} 3.0)$ electrolyte solution using a customized three-electrode electrochemical cell configuration as the reactor. The samples were diced in rectangular pieces. Light irradiation was by a $350 \mathrm{~nm}$ laser with optical power density of $0.075 \mathrm{~W} \cdot \mathrm{cm}^{-2}$. The total illuminated area was $0.175 \mathrm{~cm}^{2}$. An external voltage 
was applied to the InGaN nanowalls and InGaN layer working electrodes versus the $\mathrm{Pt}$ counter electrode and the voltage between the working electrodes and the $\mathrm{Ag} / \mathrm{AgCl}$ reference electrode was monitored. The photocurrent was measured with a standard computer controlled chrono-amperometric setup built up of a Keithley 2000 Multimeter and a Keithley 2400 Source meter. Hydrogen and oxygen were collected by a sampling loop and analyzed separately by a gas chromatography (GC) analyzer (China GC 2000), which was equipped with a TCD (thermal conductive detector) and a $3.5 \mathrm{~m}$ long molecular $5 \AA$ sieve packed column to determine the hydrogen and oxygen concentrations.

Figures 1(a) and 1(b) show the top-view scanning electron microscopy (SEM) images of the spontaneously formed InGaN nanowalls and InGaN layer. The nanowalls follow the hexagonal symmetry of the wurtzite crystal structure with growth direction along the $\mathrm{C}$-axis. The nanowalls are connected and their thickness is several $10 \mathrm{~nm}$ at the top portion. The spaces between the nanowalls are between 50 and $200 \mathrm{~nm}$. The InGaN layer is uniform and smooth on the whole substrate. Figure 1(c) shows the photograph of the experimental PEC cell setup where the formation of $\mathrm{H}_{2}$ bubbles is clearly observed on the $\mathrm{Pt}$ counter electrode during illumination.

In Fig. 2, the measured current densities as a function of the voltage versus the $\mathrm{Ag} / \mathrm{AgCl}$ reference electrode are plotted for the InGaN-nanowalls-photoelectrode and the InGaNlayer-photoelectrode under dark and illumination conditions. In the dark, the current densities are negligibly small. Under illumination, the onset voltages, at which the photocurrent densities show a rapid rise, are approximately $-0.35 \mathrm{~V}$ for both the InGaN nanowalls and the InGaN layer. The photocurrent density is about $70 \%$ larger for the InGaN nanowalls compared to that for the InGaN layer. The photocurrent densities measured for zero voltage versus the $\mathrm{Ag} / \mathrm{AgCl}$ reference electrode are $3.4 \mathrm{~mA} \mathrm{~cm}^{-2}$ for the InGaN nanowalls and $2 \mathrm{~mA} \mathrm{~cm}^{-2}$ for the InGaN layer, confirming the enhanced PEC properties of the InGaN nanowalls due to

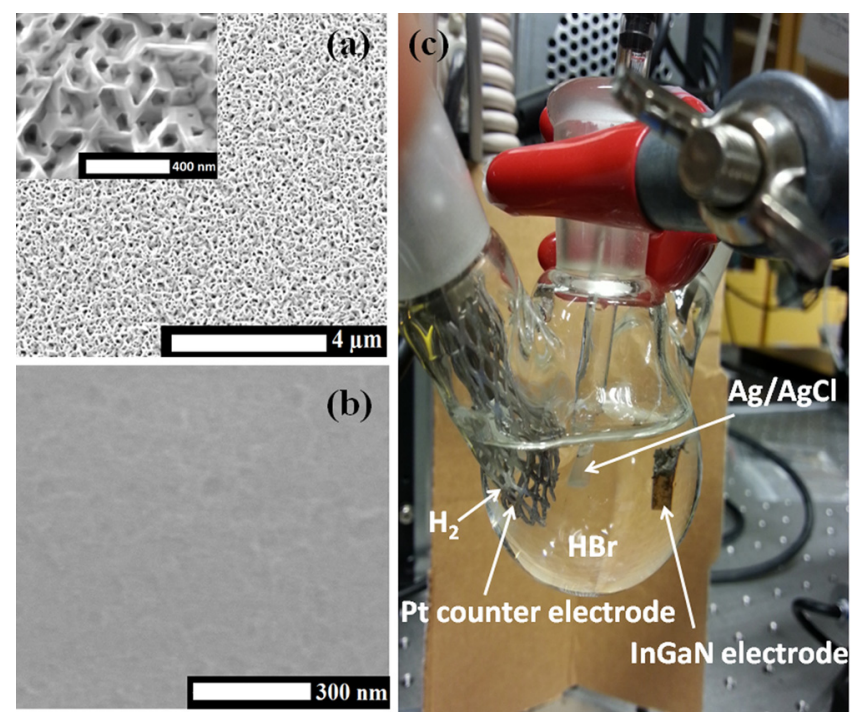

FIG. 1. Plan-view SEM images of the (a) InGaN nanowalls and (b) planar InGaN layer. The inset in (a) shows the nanowalls structure with enhanced magnification. (c) Photograph of the experimental PEC cell setup.

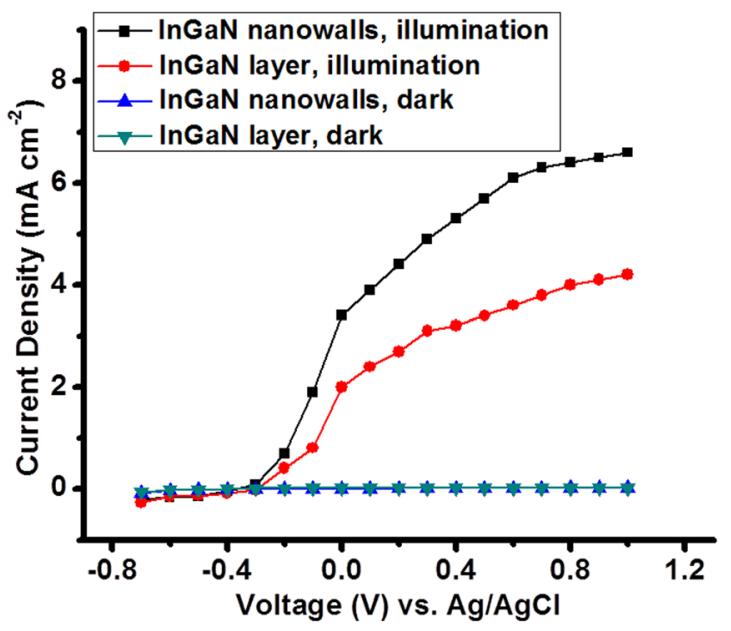

FIG. 2. Current densities as a function of voltage versus the $\mathrm{Ag} / \mathrm{AgCl}$ reference electrode in $0.5 \mathrm{~mol} \cdot 1^{-1} \mathrm{HBr}$ electrolyte solution for the InGaN-nanowalls and InGaN-layer-photoelectrodes in the dark and under $350 \mathrm{~nm}$ laser illumination with $0.76 \mathrm{~W} \mathrm{~cm} \mathrm{~m}^{-2}$ excitation power density. The measurements are performed using a three-electrode configuration.

superior light harvesting ${ }^{28,31}$ and much higher surface area ${ }^{32}$ compared to the planar InGaN layer.

Figure 3 shows the IPCE, defined as the percentage of electrons taking part in the redox reaction, with respect to the number of incident monochromatic photons, for the InGaN-nanowalls and InGaN-layer-photoelectrodes as a function of voltage versus the $\mathrm{Ag} / \mathrm{AgCl}$ reference electrode, given by ${ }^{6,33}$

$$
\begin{aligned}
\operatorname{IPCE}(\%)= & \left(1240(\mathrm{~V} \mathrm{~nm}) \times \text { photocurrent density }\left(\mathrm{mA} \mathrm{cm}^{-2}\right)\right. \\
& \times(\text { incident light wavelength }(\mathrm{nm}) \\
& \left.\times \text { light intensity }\left(\mathrm{mW} \mathrm{cm}^{-2}\right)\right)^{-1} \times 100
\end{aligned}
$$

The IPCE increases rapidly for voltages above $-0.3 \mathrm{~V}$. At zero voltage versus the $\mathrm{Ag} / \mathrm{AgCl}$ reference electrode the IPCE values for the InGaN nanowalls and InGaN layer are $16 \%$ and $9 \%$, respectively. The maximum IPCE values for the InGaN nanowalls and InGaN layer are $31 \%$ and $20 \%$ at

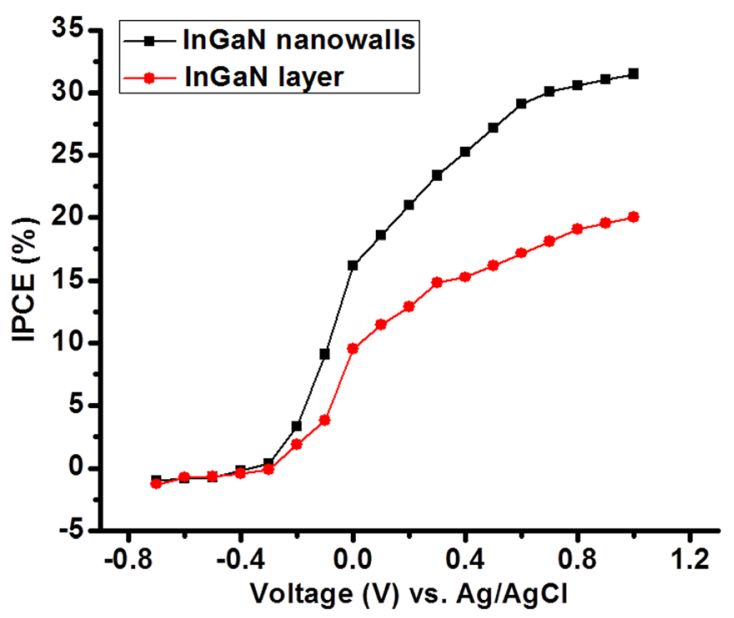

FIG. 3. IPCE of the InGaN-nanowalls and InGaN-layer-photoelectrodes under $350 \mathrm{~nm}$ laser illumination with $0.75 \mathrm{~W} \mathrm{~cm}^{-2}$ excitation power density as a function of voltage versus the $\mathrm{Ag} / \mathrm{AgCl}$ reference electrode in $0.5 \mathrm{~mol} \cdot 1^{-1} \mathrm{HBr}$ electrolyte solution. The measurements are performed using a three-electrode configuration. 


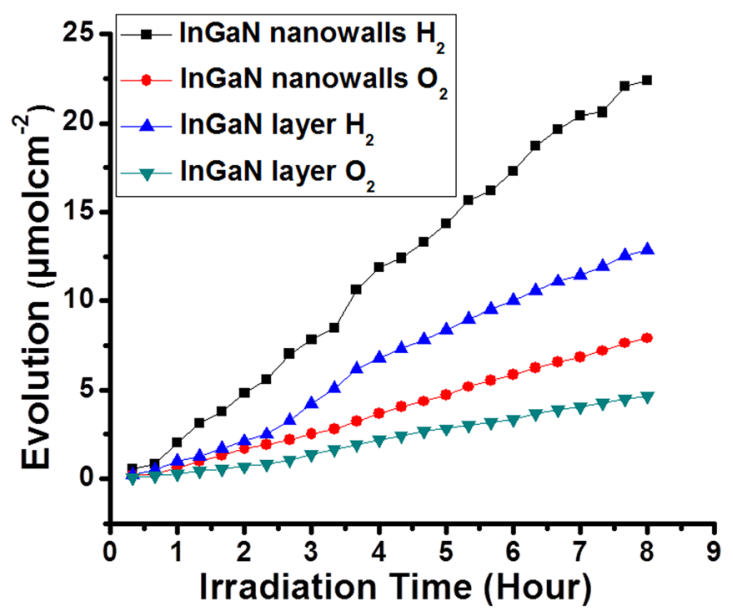

FIG. 4. $\mathrm{H}_{2}$ and $\mathrm{O}_{2}$ evolution vs. reaction time per illuminated area at zero externally applied voltage versus the $\mathrm{Pt}$ counter electrode for the InGaN-nanowalls and InGaN-layer-photoelectrodes in $0.5 \mathrm{~mol} \cdot 1^{-1} \mathrm{HBr}$ electrolyte solution. The measurements are performed in a two-electrode configuration.

$1.0 \mathrm{~V}$, respectively. $\mathrm{H}_{2}$ gas generation is clearly observed on the Pt counter electrode during illumination. The directly measured amount of hydrogen and oxygen evolved versus the reaction time is shown in Fig. 4. The total amount of $\mathrm{H}_{2}$ and $\mathrm{O}_{2}$ generated after $8 \mathrm{~h}$ of irradiation is $22.4 \mu \mathrm{mol}$ and $7.92 \mu \mathrm{mol}$ for the InGaN nanowalls, and $12.88 \mu \mathrm{mol}$ and $4.64 \mu \mathrm{mol}$ for the InGaN layers, respectively. This unambiguously evidences the splitting of water into $\mathrm{H}_{2}$ and $\mathrm{O}_{2}$ gases. The strongly enhanced performance of the nanowalls is attributed to the large surface area, enhanced light harvesting and probably capillarity effects into the nanowall bottoms and field enhancement at the nanowall tops. However, the yield of hydrogen obtained is about three times that of the oxygen yield while pure splitting of water would provide a yield of $\mathrm{H}_{2}$ to $\mathrm{O}_{2}$ gases of 2:1. This means that some hydrogen is generated through the redox reaction of the $\mathrm{HBr}$ electrolyte. It is clear that the role of the electrolyte in water splitting, not widely considered so far, needs careful attention in the future. Despite, our measurements reveal that the photocurrent and deduced $\mathrm{H}_{2}$ and $\mathrm{O}_{2}$ gases generation are very stable over time, confirming the good chemical stability of the InGaN layer and InGaN nanowalls.

To summarize, we have demonstrated superior PEC water splitting and $\mathrm{H}_{2}$ generation properties of an InGaN nanowall structure in comparison with a planar InGaN layer. This was attributed to increased light absorption by light scattering and larger surface area of the nanowalls structure together with the excellent PEC properties of InGaN. The InGaN-nanowalls-PEC cell exhibits enhanced photocurrent density, high IPCE, and a large $\mathrm{H}_{2}$ generation rate.
We thank the BBVA foundation and ETSIT UPM for financial support.

${ }^{1}$ Y. Tachibana, L. Vayssieres, and J. R. Durrant, Nat. Photonics 6, 511 (2012).

${ }^{2}$ K. Maeda and K. Domen, J. Phys. Chem. Lett. 1, 2655 (2010).

${ }^{3}$ R. van de Krol, Y. Liang, and J. Schoonman, J. Mater. Chem. 18, 2311 (2008).

${ }^{4}$ D. H. van Dorp, N. Hijnen, M. Di Vece, and J. J. Kelly, Angew. Chem. Int. Ed. 48, 6085 (2009).

${ }^{5}$ A. Kudo and Y. Miseki, Chem. Soc. Rev. 38, 253 (2009).

${ }^{6}$ A. P. Goodey, S. M. Eichfeld, K. K. Lew, J. M. Redwing, and T. E. Mallouk, J. Am. Chem. Soc. 129, 12344 (2007).

${ }^{7}$ K. Peng, X. Wang, and S. T. Lee, Appl. Phys. Lett. 92, 163103 (2008).

${ }^{8}$ J. Sun, C. Liu, and P. Yang, J. Am. Chem. Soc. 133, 19306 (2011).

${ }^{9}$ Z. Chen, D. Cummins, B. N. Reinecke, E. Clark, M. K. Sunkara, and T. F. Jaramillo, Nano Lett. 11, 4168 (2011).

${ }^{10}$ S. W. Boettcher, J. M. Spurgeon, M. C. Putnam, E. L. Warren, D. B. Turner-Evans, M. D. Kelzenberg, J. R. Maiolo, H. A. Atwater, and N. S. Lewis, Science 327, 185 (2010).

${ }^{11}$ S. W. Boettcher, E. L. Warren, M. C. Putnam, E. A. Santori, D. Turner-Evans, M. D. Kelzenberg, M. G. Walter, J. R. McKone, B. S. Brunschwig, H. A. Atwater, and N. S. Lewis, J. Am. Chem. Soc. 133, 1216 (2011).

${ }^{12}$ K. Alireza, S. Ke, J. Yi, C. Chulmin, J. Huisu, Z. Yuchun, M. Kristian, N. Perry, J. Sungho, Y. J. Gun, and W. Deli, Nano Lett. 13(7), 3017 (2013).

${ }^{13}$ P. Weisz, Phys. Today 57(7), 47 (2004).

${ }^{14}$ G. W. Crabtree, M. S. Dresselhaus, and M. V. Buchanan, Phys. Today 57(12), 39 (2004).

${ }^{15}$ J. A. Turner, Science 285, 687 (1999).

${ }^{16}$ O. Khaselev and J. Turner, J. Electrochem. Soc. 145, 3335 (1998).

${ }^{17}$ A. J. Nozik and R. Memming, J. Phys. Chem. 100, 13061 (1996).

${ }^{18}$ J. S. Hwang, T. Y. Liu, S. Chattopadhyay, G. M. Hsu, A. M. Basilio, H. W. Chen, Y. K. Hsu, W. H. Tu, Y. G. Lin, K. H. Chen, C. C. Li, S. B. Wang, H. Y. Chen, and L. C. Chen, Nanotechnology 24, 055401 (2013).

${ }^{19}$ D. F. Wang, A. Pierre, M. G. Kibria, K. Cui, X. G. Han, K. H. Bevan, H. Guo, S. Paradis, A. R. Hakima, and Z. T. Mi, Nano Lett. 11, 2353 (2011).

${ }^{20}$ Y. J. Hwang, C. H. Wu, C. Hahn, H. E. Jeong, and P. D. Yang, Nano Lett. 12, 1678 (2012).

${ }^{21}$ I. Waki, D. Cohen, R. Lal, U. Mishra, S. P. DenBaars, and S. Nakamura, Appl. Phys. Lett. 91, 093519 (2007).

${ }^{22}$ J. Benton, J. Bai, and T. Wang, Appl. Phys. Lett. 102, 173905 (2013).

${ }^{23}$ K. Fujii, K. Kusakabe, and K. Ohkawa, Jpn. J. Appl. Phys., Part 1 44, 7433 (2005).

${ }^{24}$ J. Li, J. Y. Lin, and H. X. Jiang, Appl. Phys. Lett. 93, 162107 (2008).

${ }^{25}$ C. Aprile, A. Corma, and H. Garcia, Phys. Chem. Phys. 10, 769 (2008).

${ }^{26}$ M. Zhou, S. Zhang, Y. Sun, C. Wu, M. Wang, and Y. Xie, Chem. Asian J. 5, 2515 (2010).

${ }^{27}$ J. Su, X. Feng, J. D. Sloppy, L. Guo, and C. A. Grimes, Nano Lett. 11(1), 203 (2011).

${ }^{28}$ M. Zhou, J. Bao, M. Tao, R. Zhu, Y. Zeng, Z. Wei, and Y. Xie, Chem. Commun. 48, 3439 (2012).

${ }^{29}$ P. E. D. Soto-Rodriguez, V. J. Gómez, P. Kumar, N. H. Alvi, J. M. Manuel, F. M. Morales, J. J. Jimenez, R. Garcıa, E. Calleja, and R. Nötzel, Appl. Phys. Lett. 102, 173105 (2013).

${ }^{30}$ P. E. D. Soto-Rodriguez, V. J. Gómez, P. Kumar, E. Calleja, and R. Nötzel, Appl. Phys. Lett. 102, 131909 (2013).

${ }^{31}$ H. Li, Z. Bian, J. Zhu, D. Zhang, G. Li, Y. Huo, H. Li, and Y. Lu, J. Am. Chem. Soc. 129, 8406 (2007).

${ }^{32}$ J. R. Maiolo, H. A. Atwater, and N. S. Lewis, J. Phys. Chem. C 112, 6194 (2008).

${ }^{33}$ M. Gratzel, Nature 414, 338 (2001). 